\title{
Prevalence of Abnormal Glucose Tolerance in Obese Pregnant Women - A Study from a Tertiary Care Centre
}

\author{
Ann Mary George ${ }^{1}$, Ajay Kumar ${ }^{2}$ \\ ${ }_{1,2}$ Department of Obstetrics and Gynaecology, Government Medical College, Kottayam, Kerala, India.
}

\section{ABSTRACT}

\section{BACKGROUND}

Obesity has emerged as an important risk factor in modern obstetrics and poses a major threat to pregnancy by causing complications including gestational diabetes. It also increases the risk of cardiovascular diseases and diabetes mellitus in later life. Obesity creates major technical challenges in providing maternity services too. The objective of the study was to assess the prevalence of abnormal glucose tolerance in obese pregnant women in a Government Medical College over one year.

\section{METHODS}

A prospective observational study was conducted among obese pregnant women, registered at the Outpatient department of Obstetrics and Gynaecology at the Government Medical College, Kottayam from January 2017 to December 2017. 450 women were considered for the study after satisfying inclusion and exclusion criteria. BMI was calculated using pre-pregnant weight. An oral glucose test was performed with $75 \mathrm{gm}$ glucose at 24 to 28 weeks of pregnancy after 8 hours of fasting. International Association of Diabetes and Pregnancy Study Group cut-offs i.e., fasting blood sugar values more than $92 \mathrm{mg} / \mathrm{dl}, 1 \mathrm{hr}$ value more than $180 \mathrm{mg} / \mathrm{dl}$, $2 \mathrm{hr}$ value more than $153 \mathrm{mg} / \mathrm{dl}$ were used as the criteria. Oral glucose tolerance was considered abnormal if any of the above values were impaired.

\section{RESULTS}

The prevalence of abnormal glucose tolerance among the 450 pregnant women was $35.6 \%$. The incidence of abnormal GTT increased with increasing age and in those with a history of menstrual irregularities and infertility treatment. No relation was found between economic status, family history of diabetes, preeclampsia and abnormal GTT.

\section{CONCLUSIONS}

Obesity turns to be a menace in the reproductive life of women that begins by affecting the fertility, continues to cause complications in pregnancy, increases morbidity in the long-term future and reduces the quality of life. Since more than one-third of the study population was affected by gestational diabetes, active intervention to reduce the weight preconceptionally is needed.

\section{KEY WORDS}

Obesity, Glucose Tolerance Test, Gestational Diabetes Mellitus, Body Mass Index, Pregnancy
Corresponding Author:

Dr. Ajay Kumar,

Additional Professor,

Department of $O B G$,

Government Medical College,

Kottayam, Kerala, India.

E-mail: ajaymanju2000@gmail.com

\section{DOI: $10.14260 / \mathrm{jemds} / 2021 / 762$}

How to Cite This Article:

George AM, Kumar A. Prevalence of abnormal glucose tolerance in obese pregnant women - a study from a tertiary care centre. J Evolution Med Dent Sci 2021;10(44):3769-3774, 10.14260/jemds/2021/762 DOI:

Submission 21-09-2021,

Peer Review 15-11-2021,

Acceptance 22-11-2021,

Published 30-11-2021.

Copyright (c) 2021 Ann Mary George et al. This is an open access article distributed under Creative Commons Attribution License [Attribution 4.0 International (CC BY 4.0)] 


\section{BACKGROUND}

Obesity, according to World Health Organisation (WHO), is defined as an abnormal or excessive accumulation of fat that may impair health.

Body Mass Index (BMI), is a simple metric that is commonly used to classify overweight and obesity in adults. It is defined as a person's weight in kilograms divided by the square of height in metres $\left(\mathrm{kg} / \mathrm{m}^{2}\right)$.

According to the World Health Organization, individuals with body mass indices (BMIs) of $25.0 \mathrm{~kg} / \mathrm{m} 2$ to $29.9 \mathrm{~kg} / \mathrm{m} 2$ are considered overweight and BMIs of $30.0 \mathrm{~kg} / \mathrm{m} 2$ and above are labelled as obese. However, since Asians tend to have higher amounts of abdominal fat at lower BMIs, these cut-offs may be insufficient in identifying Asian individuals with a high risk of obesity-related morbidity and mortality. In 2000 the Western Pacific Regional Office of WHO (WPRO) proposed an alternative definition of overweight (BMI 23.0 24.9) and obesity (BMI $\geq 25.0$ ) for Asian populations. ${ }^{1}$ At any given BMI above $25.0 \mathrm{~kg} / \mathrm{m} 2$, the corresponding mortality risk was higher among Asians in comparison to their US counterparts.

The Indian Ministry of Health and Family Welfare reduced diagnostic cut-offs for Indian BMIs to $23 \mathrm{~kg} \mathrm{~m}^{2}$ (from 25 ) for overweight and $25 \mathrm{~kg} / \mathrm{m} 2$ (from 30 ) for obesity and the standard waist circumference to $90 \mathrm{~cm}$ in men and $80 \mathrm{~cm}$ in women (internationally accepted waist circumference cutoffs are $102 \mathrm{~cm}$ in men and $88 \mathrm{~cm}$ in women). These standards have been published in the ministry's Consensus Guidelines for the Prevention and Management of Obesity and Metabolic Syndrome in October 2008.\{Citation\}

As per WHO in 2016, more than 1.9 billion adults aged 18 years and above were overweight. Of these over 650 million adults were obese. $39 \%$ of adults aged 18 years and over (39 $\%$ of men and $40 \%$ of women) were overweight. Overall, 13 $\%$ of the world's adult population (11\% of men and $15 \%$ of women) were obese in 2016. The worldwide prevalence of obesity nearly tripled between 1975 and 2016. Obesity contributes to the global burden of chronic disease, disability and premature death. Many low and middle-income countries are now facing a "double burden" of the disease. ${ }^{1}$

While the low-income countries continue to deal with the problems of infectious diseases and undernutrition, they are also experiencing a rapid surge in risk factors for noncommunicable diseases such as obesity and overweight, particularly in urban settings. It is not uncommon to find undernutrition and obesity co-existing within the same country, the same community, and the same household. Children in low and middle-income countries are more vulnerable to inadequate prenatal, infant, and young child nutrition. At the same time, these children are exposed to high fat, high sugar, high salt, energy-dense and micronutrient-poor foods, which tend to be lower in cost but also lower in nutrient quality. These dietary patterns, in conjunction with lower levels of physical activity, result in sharp increase in childhood obesity while issues pertaining to undernutrition remain unsolved. Type 2 diabetes mellitus, cardiovascular diseases (CVD), hypertension and heart diseases are the common chronic co-morbidities associated with an overweight or obese health condition. Moreover, several studies reveal that the level and risk factors of overweight or obesity significantly differ for men and women.
In 138 of 194 countries for which the WHO reports obesity statistics, women are more than $50 \%$ more likely to be obese. ${ }^{1}$

Maternal obesity has emerged as an important risk factor in modern obstetrics worldwide, especially among the Asian population. In the short-term, it has been associated with an increase in pregnancy complications such as gestational diabetes mellitus (GDM), pre-eclampsia, post-term pregnancy, emergency caesarean deliveries, postpartum haemorrhage, pelvic infections, urinary tract infections, wound infections, foetal macrosomia, stillbirth, and thrombosis. In the long term, it is associated with an increased risk of diabetes mellitus, cardiovascular disease for the woman, and an increased risk of childhood obesity for her offspring. ${ }^{2}$ Severe obesity poses many technical difficulties for providing services during maternity. Intravenous access, regional anaesthesia, etc. become more difficult. The available hospital facilities and equipment are found inadequate for the management of women with severe obesity..$^{3-4}$

Incidences of gestational diabetes mellitus in obese pregnant women are higher than that of the general population. Women who are overweight or obese are more likely to develop GDM.5,6 Maternal risks such as increased rate of the operative/caesarean delivery, hypertensive disorders, risk of type 2 DM, metabolic syndrome, obesity, cardiovascular diseases, and recurrent GDM are common for those mothers with GDM. Similarly, risk of macrosomia, shoulder dystocia, and neurological and skeletal injuries, neonatal hyperbilirubinemia, hypoglycaemia, electrolyte imbalances, respiratory distress etc. are common for infants born to diabetic mothers.

Early diagnosis and optimum treatment of gestational diabetes in a high-risk population like obese individuals can bring about better outcomes for both the mother and baby. The use of IADPSG criteria for the diagnosis of gestational diabetes has improved the pregnancy outcome and costeffectiveness. Understanding the prevalence of abnormal glucose tolerance in obese pregnant women will help the clinicians to change their attitude and practice in the treatment of this high-risk population. ${ }^{7}$ The objective of the study was to assess the prevalence of abnormal glucose tolerance in obese pregnant women.

\section{METHODS}

A prospective cross-sectional study was conducted for 19 months from January 2017 to July 2018 in the Department of Obstetrics and Gynaecology, Govt. Medical College, Kottayam, a 1500 bedded hospital caring for patients from Kottayam, Idukki, Alappuzha, Pathanamthitta districts of Kerala State, India. The study was started after getting clearance from the institutional ethical committee. All obese pregnant women who attended the outpatient department of Obstetrics \& Gynaecology in Government Medical College, Kottayam during the study period with age less than 40 years and a body mass index of more than $25 \mathrm{~kg} / \mathrm{m} 2$ (calculated from their prepregnant weight) were included in the study. Body mass index more than $25 \mathrm{~kg} / \mathrm{m} 2$ was taken as the diagnostic cut off for obesity according to the Ministry of Health and Family Welfare, India. Pregnant women less than 40 years with polycystic ovarian syndrome (PCOS), metabolic 
syndrome, previous history of gestational diabetes mellitus were excluded from the study.

\section{Sample Size}

Various studies provide different values for the prevalence of GTT in pregnant women. For the study, it was taken as $19 \%$ (patients with abnormal GTT in pregnancy). ${ }^{8}$

The formula used is-

$n=\frac{Z_{1-\frac{\alpha}{2}}^{2} P(1-P)}{(\varepsilon P)^{2}}$

$n=\frac{0.19^{2} \times 0.19 \times 0.81}{\left(\frac{20}{100} \times 0.19\right)^{2}}=409$

Where

P: Expected proportion of IGTT in obese

$\varepsilon$ : Relative precision (taken as $20 \%$ of P)

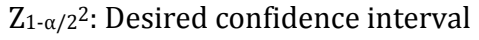

The final sample size was taken as 450 anticipating a dropout rate of $10 \%$.

\section{Study Procedure}

Gestational age was estimated from the last menstrual period (LMP) and was confirmed by a dating scan. Body mass index was calculated by dividing pre-pregnant weight in kilograms by height in metre square. In the study, first trimester weight was taken as the prepregnant weight for the purpose of calculation. Oral glucose tolerance test was performed at 2428 weeks of pregnancy. It was done after 8 hours of fasting. A fasting blood sugar value was checked before the glucose load. After 75 gm glucose load, 2 blood samples were taken and checked for abnormal glucose tolerance. Abnormal oral glucose tolerance was detected according to the International Association of Diabetes and Pregnancy Study Groups criteria, i.e., fasting blood sugar values more than $92 \mathrm{mg} / \mathrm{dl}, 1 \mathrm{hr}$ value more than $180 \mathrm{mg} / \mathrm{dl}, 2 \mathrm{hr}$ value more than $153 \mathrm{mg} / \mathrm{dl} .{ }^{9}$ Oral glucose tolerance was considered abnormal if any of the above values were impaired.

\section{Statistical Analysis}

Data collection and documentation were done in the study setting by personal interviews and investigations. Data was entered in MS Excel and analysed using SPSS 24 software. A chi-square test was used to analyse the association between abnormal GTT and variables.

\section{RESULTS}

\begin{tabular}{|ccc|}
\hline Obstetric Code & Number of Women & Percentage \\
Primigravida & 162 & 36.0 \\
Nulliparous & 49 & 10.9 \\
Primiparous & 191 & 42.4 \\
Multiparous & 48 & 10.7 \\
Total & $\mathbf{4 5 0}$ & $\mathbf{1 0 0 . 0}$ \\
\hline \multicolumn{2}{c}{} \\
\hline
\end{tabular}

In this study, the majority of participants were primiparous followed by primigravida.

\section{Family History of Diabetes Mellitus}

\begin{tabular}{|ccc|}
\hline Family History of Diabetes Mellitus & Number of Women & Percentage \\
Yes & 183 & 40.7 \\
No & 267 & 59.3 \\
Total & $\mathbf{4 5 0}$ & $\mathbf{1 0 0 . 0}$ \\
\hline Table 2. Family History of Diabetes Mellitus \\
\hline \multicolumn{2}{|c}{} \\
\hline \multicolumn{2}{|c}{} \\
\hline
\end{tabular}

$40.7 \%$ of participants came from families in which parents had a history of diabetes mellitus.

\section{Prevalence of Abnormal Glucose Tolerance}

\begin{tabular}{|ccc|}
\hline $\mathbf{7 5}$ GM GTT Test & Number of Women & Percentage \\
Normal & 290 & 64.4 \\
Abnormal & 160 & 35.6 \\
Total & $\mathbf{4 5 0}$ & $\mathbf{1 0 0 . 0}$ \\
\hline Table 3. Abnormal Glucose Tolerance among Participants \\
\hline
\end{tabular}

Abnormal Glucose Tolerance was present in $35.6 \%$ of the study population i.e., women with BMI greater than or equal to $25 \mathrm{~kg} / \mathrm{m}^{2}$.

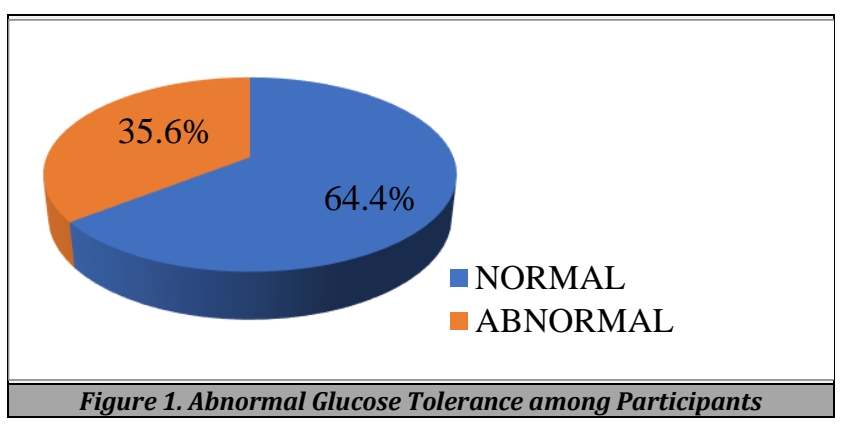

Age Groups and Relation with Abnormal GTT

\begin{tabular}{|c|c|c|c|c|}
\hline \multirow{2}{*}{ Age Group } & \multicolumn{2}{|c|}{ GTT_75 } & \multirow{2}{*}{ Total } & \multirow{2}{*}{ Chi-Square Value } \\
\hline & Normal & Abnormal & & \\
\hline \multirow[b]{2}{*}{$<20$} & 3 & 0 & 3 & \multirow{12}{*}{$\begin{array}{c}12.504 \\
P=0.014\end{array}$} \\
\hline & $100.0 \%$ & $.0 \%$ & $100.0 \%$ & \\
\hline \multirow{2}{*}{$20-25$} & 83 & 26 & 109 & \\
\hline & $76.1 \%$ & $23.9 \%$ & $100.0 \%$ & \\
\hline \multirow[b]{2}{*}{$25-30$} & 119 & 71 & 190 & \\
\hline & $62.6 \%$ & $37.4 \%$ & $100.0 \%$ & \\
\hline \multirow{2}{*}{$30-35$} & 59 & 48 & 107 & \\
\hline & $55.1 \%$ & $44.9 \%$ & $100.0 \%$ & \\
\hline \multirow{2}{*}{$35-40$} & 26 & 15 & 41 & \\
\hline & $63.4 \%$ & $36.6 \%$ & $100.0 \%$ & \\
\hline \multirow{2}{*}{ Total } & 290 & 160 & 450 & \\
\hline & $64.4 \%$ & $35.6 \%$ & $100.0 \%$ & \\
\hline
\end{tabular}

A chi-square test was used to find the association between each variable and abnormal GTT. A significant association was found with age groups and abnormal GTT. Increasing age groups showed a trend towards more abnormal GTT.

\section{Classes of Obesity and Abnormal GTT}

According to the Steering Committee of the Regional Office for the Western Pacific Region of the WHO, the International Association for the Study of Obesity and the International Obesity Task Force, which proposed the appropriateness of classification of obesity in Asia in the year 2000, the participants were categorised into two classes of obesity based on their BMI figures.

1. Class I (BMI: $25-29.9 \mathrm{~kg} / \mathrm{m}^{2}$ )

2. Class II (BMI $\left.>/=30 \mathrm{~kg} / \mathrm{m}^{2}\right)$ 
Family History of Diabetes Mellitus and Abnormal GTT

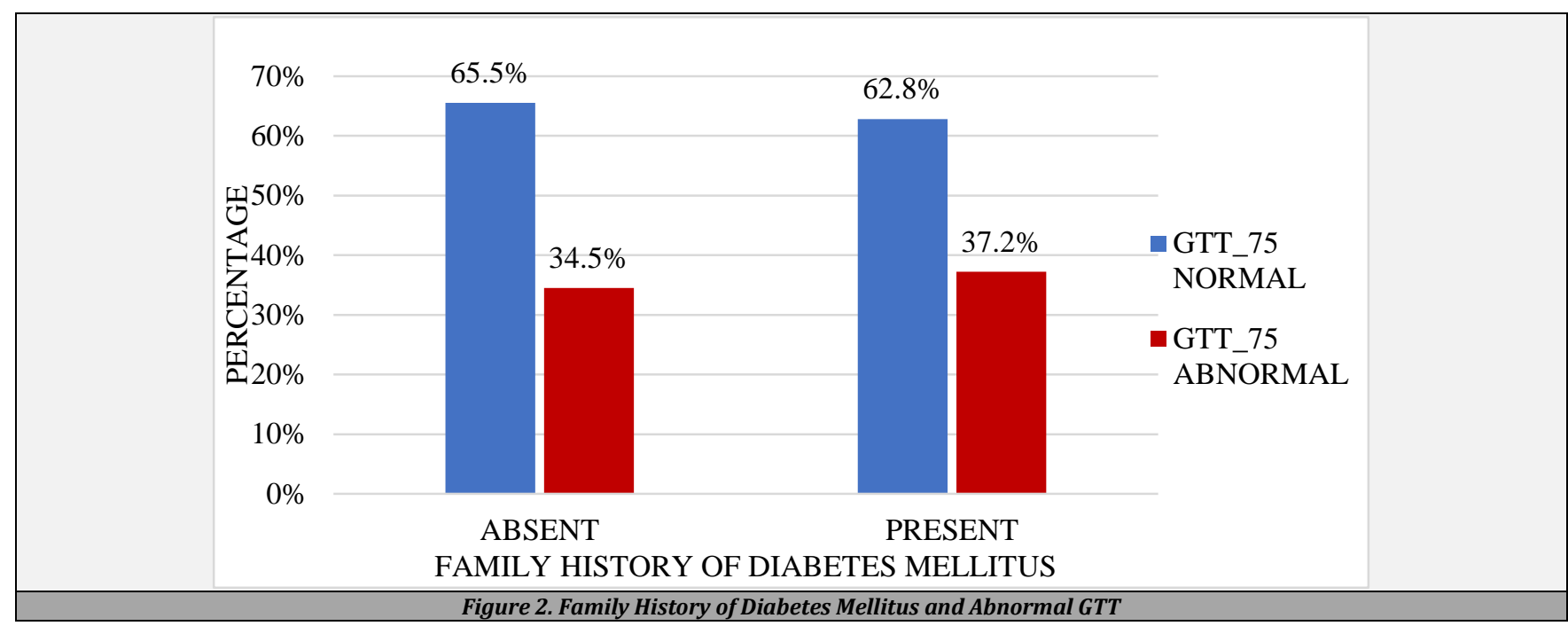

There is not much increase in the prevalence of abnormal GTT in those participants with a family history of diabetes mellitus.

\section{Hypertension and Abnormal GTT}

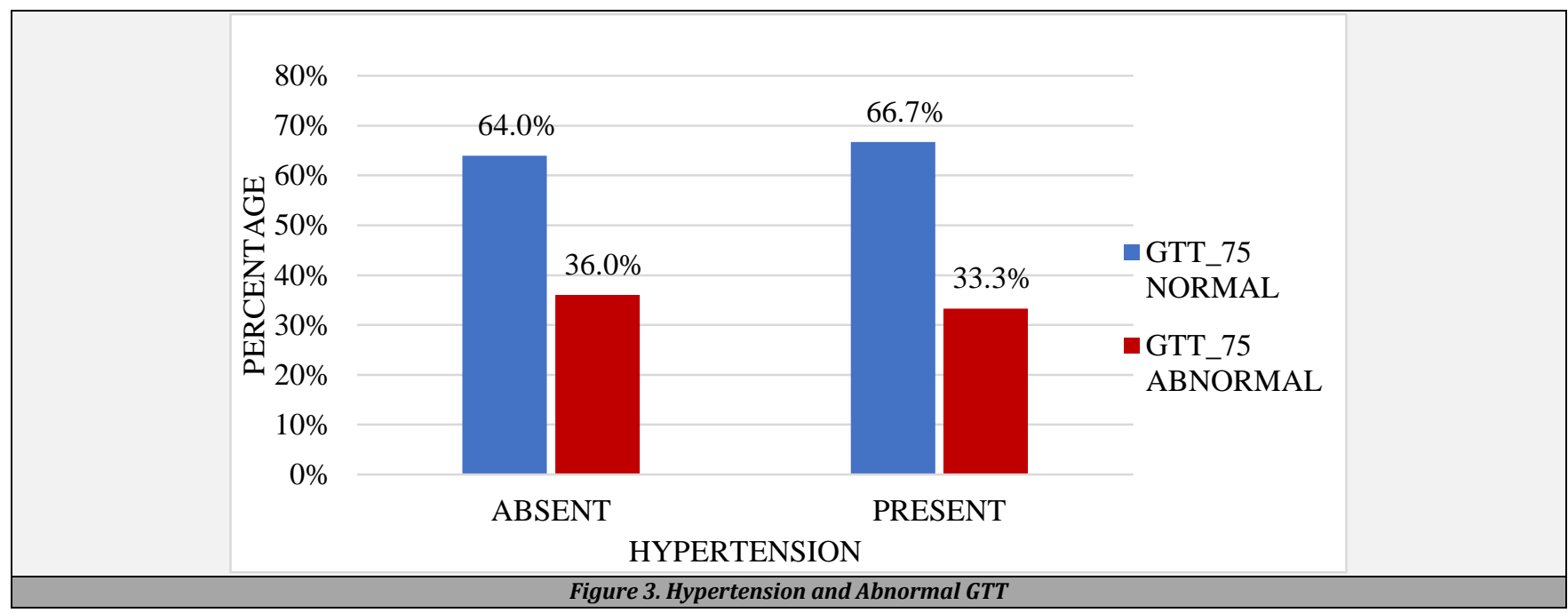

The prevalence of abnormal GTT is almost equally distributed among the 2 groups with and without gestational hypertension or preeclampsia.

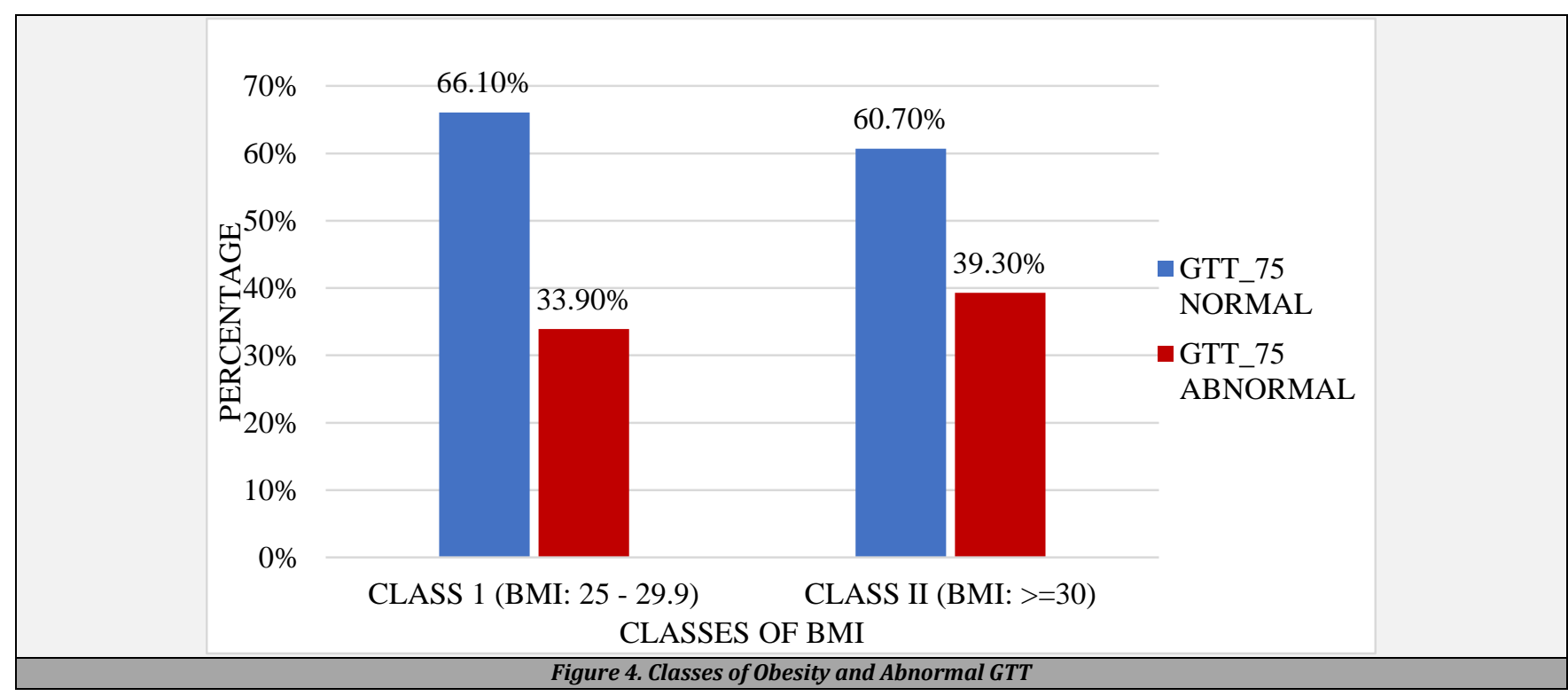




\section{DISCUSSION}

Obesity in pregnancy is associated with unfavourable outcomes for both mother and child. Approximately one-third of all women of childbearing age are overweight or obese. The risk of pregnancy-associated disorders increases with the increasing severity of obesity. A pre-pregnancy BMI $>25$ $\mathrm{kg} / \mathrm{m}^{2}$ is associated with an increased risk of manifestation of gestational diabetes mellitus. India has the highest number of diabetics; however, no national data is available on the disease burden of GDM. A systematic review and metaanalysis were conducted to estimate the gestational diabetes mellitus prevalence in Indian women. The GDM prevalence ranged from as low as $0.6 \%$ to as high as $27.3 \%$. The pooled estimate of the GDM prevalence among Indian women was $9.3 \%$ (95 \% Confidence Interval: 7.6, 11.1). The GDM prevalence was $3 \%, 11 \%$ and $12 \%$ in the study period 1991-2000, 2001-2010, and 2011-2015 respectively. ${ }^{1}$

The prevalence of gestational diabetes in obese pregnant women varied in different studies across the country. In this study, the prevalence was $35.6 \% .122(76.2 \%)$ of 160 participants with abnormal GTT took diet control and 38 (23.8\%) were administered either insulin or oral hypoglycaemic agents (OHA). The incidence of abnormal glucose tolerance was increased in nulliparous patients (23 out of 49 participants) that may point to an association between spontaneous abortions and probable insulin resistance in obesity. There is no relationship between economic status, family history of diabetes, gestational hypertension or preeclampsia and abnormal GTT. As the age increases, the chances of GTT to become abnormal also increase and it is highest in 30-35 years of age (44.9\%). The incidence of abnormal GTT is increased in those with a history of menstrual irregularities (42.2\%) and infertility treatment (42.6\%).

A prospective comparative study at the Department of Obstetrics and Gynaecology, Institute of Maternal and Child Health, Government Medical College, Calicut was conducted by Seeniammal P., Chellamma V. K., Umadevi N. in 2017 on the effect of body mass index on pregnancy outcomes in normal and overweight women. The incidence of gestational diabetes in the study group (BMI $>25 \mathrm{~kg} / \mathrm{m}^{2}$ ) was $8 \%$. The combined incidence of gestational hypertension and preeclampsia was $58 \%$ in the study group whereas in our study it was $18 \% .^{10}$

A study conducted on Effect of Maternal Body Mass Index on Pregnancy Outcome by H S Ashok Kumar, V K Chellamma in the Institute of Maternal and Child Health, Government Medical College, Kozhikode, for 1 year from March 2012 to February 2013 showed an incidence of $7.4 \%$ for gestational diabetes in obese pregnant women $\left(>25 \mathrm{~kg} / \mathrm{m}^{2}\right) .{ }^{11}$

A study was conducted on the prevalence of gestational diabetes mellitus in Azeezia Medical College, Kollam by $\mathrm{K}$ Sreekanthan, A Belicita, K Rajendran, Anil Vijayakumar. Out of 71 pregnant women, $12(17 \%)$ were having diabetes. 30 (42.3\%) had BMI between 25-29.9 and 6 (8.5 \%) had BMI above 30 . The prevalence of gestational diabetes in obese was $11 \% .12$

In the prospective study conducted by Amrutha R. Thota, Ambarisha Bhandiwad, Vineet Sakhireddy on short term effects of maternal obesity on mother and foetus at JSS
Medical College, Mysore, BMI $>30 \mathrm{~kg} / \mathrm{m}^{2}$ was taken as cut off for obesity. $35.7 \%$ of 314 obese women developed gestational diabetes whereas only $3.1 \%$ of non-obese developed GDM. In our study, $76.2 \%$ of diabetics took diet control and $23.8 \%$ were administered insulin. $66 \%$ of diabetics in the obese group were advised diet control and 33 $\%$ with insulin. ${ }^{13}$ In our study, there is no increased incidence of coexistence of hypertension and GDM as the classes of obesity increase, but in this study, it showed an increasing trend.

A study was conducted on the prevalence of Gestational Diabetes Mellitus in South India (Tamil Nadu) - a communitybased study by Seshiah, V Balaji, Madhuri S Balaji, A Paneerselvam, T Arthi, M Thamizharasi, Manjula Datta in 2008. There was a consistent increase in the prevalence of GDM in all three areas (rural, semi-urban and urban) as BMI increased and the trend was statistically significant $(\mathrm{P}<$ 0.0001). Among the GDM women, the highest prevalence was observed in women with BMI $\geq 25 \mathrm{~kg} / \mathrm{m} 2$, and it was $28.4 \%$ in an urban area, $23.8 \%$ in semi-urban areas and $16.1 \%$ in rural areas. The prevalence of GDM was $7 \%$ more in women with BMI of $\geq 25 \mathrm{~kg} / \mathrm{m} 2$ as compared to women with BMI $23.0-24.9 \mathrm{~kg} / \mathrm{m} 2$ in urban and semi-urban areas and this difference was $5 \%$ in rural areas. ${ }^{14}$

In a study conducted on maternal obesity and pregnancy outcome by Debasmita Mandal, Saroj Mandal, Abhijit Rakshit, Ram Prasad Dey, Subhash Chandra Biswas, Amal Banerjee in Indian pregnant women in 2011, out of 422 obese pregnant women, 82 (19.43 \%) had gestational diabetes. ${ }^{10}$

A study was conducted to assess the prevalence of carbohydrate intolerance of varying degrees in pregnant females registered at a tertiary care hospital in Western India (Maharashtra) by Swami, Mehetre, et al. 2008. This study revealed that as pre-pregnancy BMI [OR:1.43; CI (0.65 -3.14), $(\mathrm{P}=0.0316)]$ increased; the prevalence of GDM, IGGT also increased. 15

A study on the prevalence of gestational diabetes mellitus \& associated risk factors at a tertiary care hospital in Haryana by Rajesh Rajput, Yogesh Yadav, Smiti Nanda and Meena Rajput showed a significant association between prevalence of GDM and increasing BMI of participants $(\mathrm{P}<0.001)$. Women having $\mathrm{BMI}>25 \mathrm{~kg} / \mathrm{m}^{2}$ had GDM 11/50 (22\%) compared to $11 / 232(4.7 \%)$ in women with BMI $<18.5$ $\mathrm{kg} / \mathrm{m}^{2}$. Ten of 60 (16.7\%) women with pre-pregnancy weight above $60 \mathrm{~kg}$ were found to have GDM compared to $14 / 157$ $(8.9 \%)$ in women with a weight between 51 and $60 \mathrm{~kg}$, $16 / 291$ (5.5 \%) in women with a weight between 41 and 50 $\mathrm{kg}$ and only $3 / 99$ (3\%) in women with weight less than or equal to 40 kg. 16

\section{CONCLUSIONS}

Obesity turns to be a menace in the reproductive life of women that begins by affecting their fertility, continues to cause complications in pregnancy and increases morbidity in the long-term future and reduces the quality of life. Since more than one-third of the study population was affected by gestational diabetes, active intervention to reduce the weight preconceptionally is needed. 
Data sharing statement provided by the authors is available with the full text of this article at jemds.com.

Financial or other competing interests: None.

Disclosure forms provided by the authors are available with the full text of this article at jemds.com.

\section{REFERENCES}

[1] Correa A, Gilboa SM, Besser LM, et al. Diabetes mellitus and birth defects. Obstetric Anesthesia Digest 2009;29(1):40-1.

[2] World Health Organization. International Association for the Study of Obesity, International Obesity Task Force. The Asia-Pacific perspective: redefining obesity and its treatment. World Health Organization 2000:15-21.

[3] Bairwa M, Yadav V, Misra P, et al. Prevalence of Gestational Diabetes Mellitus in India: A Systematic Review and Meta-analysis (Oral Presentation) 2017.

[4] Seeniammal P, Chellamma VK, Umadevi N. A comparative study of the effect of body mass index on pregnancy outcomes in normal and overweight women. International Journal of Reproduction, Contraception, Obstetrics and Gynecology 2017;6(4):1550-4.

[5] India reworks obesity guidelines, BMI lowered igovernment.in. [cited 2018 Aug 10]. Available from: http://www.igovernment.in/articles/26259/indiareworks-obesity-guidelines-bmi-lowered

[6] WHO. Obesity. WHO. [cited 2018 Jul 15]. http://www.who.int/gho/ncd/risk_factors/obesity_text /en/

[7] International Association of Diabetes and Pregnancy Study Groups Consensus Panel. International association of diabetes and pregnancy study groups recommendations on the diagnosis and classification of hyperglycemia in pregnancy. Diabetes Care 2010;33(3):676-82.
[8] Institute of Obstetricians and Gynaecologists, Royal College of Physicians of Ireland and Clinical Strategy and Programmes Directorate, Health Service Executive, Obesity and pregnancy clinical practice guideline June 2011. Available from: https://rcpi-livecdn.s3.amazonaws.com/wpcontent/uploads/2016/05/2.-Obesity-andPregnancy.pdf

[9] Morin KH, Reilly L. Caring for obese pregnant women. J Obstet Gynecol Neonatal Nurs. 2007;36(5):482-9.

[10] Mandal D, Manda S, Rakshi A, et al. Maternal obesity and pregnancy outcome: a prospective analysis. J Assoc Physicians India 2011;59:486-9.

[11] Kumar HSA, Chellamma VK. Effect of maternal body mass index on pregnancy outcome. International Journal Of Scientific Study 2017;4(10):81-4.

[12] Sreekanthan K, Belicita A, Rajendran K, et al. Prevalence of gestational diabetes mellitus in a medical college in south India: a pilot study. 2014.

[13] Thota AR, Bhandiwad A, Sakhireddy V. Short term effects of maternal obesity on mother and fetus: a prospective study. International Journal of Reproduction, Contraception, Obstetrics and Gynecology 2018;7(8):3097-102.

[14] Seshiah V, Balaji V, Balaji MS, et al. Gestational diabetes mellitus manifests in all trimesters of pregnancy. Diabetes Res Clin Pract 2007;77(3):482-4.

[15] Swami SR, Mehetre R, Shivane V, et al. Prevalence of carbohydrate intolerance of varying degrees in pregnant females in western India (Maharashtra)--a hospitalbased study. J Indian Med Assoc 2008;106(11):712-4.

[16] Rajput R, Yadav Y, Nanda S, et al. Prevalence of gestational diabetes mellitus \& associated risk factors at a tertiary care hospital in Haryana. Indian J Med Res 2013;137(4):728-33. 